\title{
Smart, smarter, smartest... the consumer meets the smart electrical grid
}

\author{
Laurence Hauttekeete, Jeroen Stragier, Wouter Haerick and Lieven De Marez
}

\begin{abstract}
In the current debate towards a more energy efficient supply and demand in household settings, notions such as smart grids, smart meters and smart appliances are of main importance. Different stakeholders are involved, but often neglected is the exact role of the customer, or more specific, his opinion, attitude, drivers or barriers towards these developments. As a consequence, this paper employs a user-centric perspective. It addresses issues such as the effect of giving personalized feedback on energy consumption and refers to studies that have been conducted concerning a possible future implementation of smart meters and smart appliances. Furthermore, it describes an innovative combination of different methodological techniques on the level of energy monitoring and user interrogation. This methodological set-up will allow to gain a clear insight in the willingness of consumers to accept different kinds of measures when it comes to smart metering and smart appliances in their daily life, as to have an efficient user adoption in the future.
\end{abstract}

Index Terms-consumer behavior, energy consumption, smart appliances, smart grid

\section{INTRODUCTION}

SMART electrical grids are high on the agenda. They refer $S_{\text {to }}$ the electricity network of the future, allowing an intelligent monitoring and/or controlling of electricity streams. In order to have an efficient energy demand management or demand side management whereby the energy use of different types of consumers can be adapted, the implementation of smart meters is strongly promoted by political as well as economic organizations [1]. In the debate towards a more energy efficient supply and demand in household settings, several ideas about smart meters and smart appliances come

Manuscript received February 12, 2010. This work was supported by the 'Agentschap voor Innovatie door Wetenschap en Technologie (IWT Flanders). IWT-Vlaanderen, Linear+ project.

L. Hauttekeete works at the Research Group for Media \& ICT (MICT) IBBT - Ghent University, Ghent, 9000 Belgium (corresponding author, phone: 0032-92649183; fax: 0032-92646992; e-mail: Laurence.hauttekeete@ ugent.be).

J. Stragier works at the Research Group for Media \& ICT (MICT) - IBBTGhent University, Ghent, 9000 Belgium (e-mail: jeroen.stragier@ugent.be).

W. Haerick works at the Department of Information Technology (INTEC)

IBBT- Ghent University, Ghent, 9000 Belgium (e-mail: wouter.haerick@ugent.be).

L. De Marez works at the Research Group for Media \& ICT (MICT) IBBT - Ghent University, Ghent, 9000, Belgium (e-mail: lieven.demarez@ugent.be) to the surface, ranging from alternative forms of billing to the implementation of washing machines that postpone the washing activity because of energy reasons.

In the current discussion about smart meters and smart appliances different kinds of stakeholders are involved: energy suppliers, political institutions, green parties, smart device manufacturers,... But often neglected is the exact role of the consumer, or more specific, his opinion, attitude, drivers or barriers towards these developments. In other words, if we want to change the energy consumption pattern and make it smarter, this should not only be done from a top-down perspective.

As a consequence, this paper employs a user-centric perspective. It addresses issues such as the effect of giving personalized feedback on energy consumption and refers to studies that have been conducted concerning a possible future implementation of smart meters and smart appliances. These two topics clearly demonstrate that a well-considered user involvement and communication towards this user are prerequisites for better energy demand management.

In this perspective, a more thorough study of the user remains indispensable, in order to gain insight in the willingness of consumers to accept different kinds of measures when it comes to smart metering and smart appliances in their daily life, so as to have an efficient user adoption in the future. This paper addresses this issue by describing in detail the innovative methodological set-up of a large-scale face-to-face user survey which will be conducted from March 2010 until May 2010 in Flanders, thereby combining both energy monitoring and user interrogation and keeping in mind the necessity of personalized feedback mechanisms.

\section{DO NOT NEGLECT THE USER}

\section{A. Effects of feedback on energy consumption}

Households account for approximately $25 \%$ of the Belgian energy consumption. The largest part of this energy is used for the heating of the house, the rest is used for electric appliances and water heating (www.energiesoorten.be). Therefore, energy efficiency measures regarding insulation and efficient use of electric appliances will become increasingly important in the residential sector. Mansouri-Azar et al. [2] found that a majority of the their respondents did not even know which of their electric appliances consumed most energy. At the time 
the research was carried out, the lighting, freezer and dishwasher were the most consuming appliances in the UK households. Nonetheless, most of the respondents named the washing machine in their top three. Thus, if people have no insight in the amount of energy their appliances consume, it is hard to reduce their energy consumption. Indeed, the use of electric appliances can be done in a more energy efficient way. To do this, one can give the consumer tons of information on how to save energy. Another way is to actively address them, giving important information on energy consumption while using the electric appliances.

Previous research (a.o. [3],[4],[5],[6],[7]) has shown that active feedback on energy consumption is effective to encourage households to take energy conserving measures. Van Raaij and Verhallen [8] distinguish three main functions of feedback:

(1) learning: the provided feedback gives the consumer information on the results of certain actions;

(2) habit formation: the feedback helps in forming certain new habits with regard to energy conservation. These habits should remain when the feedback is removed;

(3) internalization of behaviour: feedback helps to create new attitudes and habits that become embedded in a person's behaviour. These habits and attitudes will influence energyrelated actions in situations where the feedback will not be present. In the following paragraphs we will discuss the major results of research that has been carried out in this area.

Brandon and Lewis [9] placed 120 households in 6 feedback conditions: (1) comparison of own household energy consumption to that of other households, (2) comparison of own energy consumption, on different moments in time, (3) financial values (information on consumption and costs), (4) environmental values (such as the relation between energy consumption and the effects on the environment, e.g. global warming), (5) leaflet presentation (information on energy saving measures) and (6) computer presentation of individual household data. A $7^{\text {th }}$ group did not receive any feedback and served as a control group. A survey was also taken to gain insights on environmental attitudes, energy saving measures and socio-demographic information. The results showed that the computer group performed better than the other experimental groups. The energy consumption in this group decreased significantly compared to the control group: $80 \%$ of the households in the PC condition reduced their energy consumption significantly. In the other experimental conditions, the decrease was less significant. Ueno et al. [4] installed an energy consumption information system (ECOIS) at nine houses. This system measured electric power consumption for the house and for each home appliance separately at intervals of 30 minutes. The household members could access their consumption by means of a computer. As a result, the researchers saw a 9\% reduction in the household's power consumption. Also, the energy awareness that resulted through the feedback translated into a different behaviour towards other appliances besides those that could be monitored on the screen, which is consistent with Van Raaij and Verhallen's third function of feedback [8].

Consistent with these findings, Wood and Newborough [7] found that dynamic energy consumption feedback via smart meters and displays reduced the consumption by $10 \%$ up to
$20 \%$ within the households that were monitored. They suggest that feedback can be given at best during or immediately after the use of an appliance. This way, the consumers are provided with immediate updates on their energy consumption patterns. Previous research [10],[11], has shown that this instant feedback is indeed very effective.

Direct feedback would imply that it would be given close to the electric appliance, or by the appliance itself. The next paragraph focuses on these next generation electric appliances or "smart appliances".

\section{B. Smart appliances and the user}

A growing increase in the purchase of electric appliances causes a growing demand of energy in households. Inefficient use of these appliances causes a waste of energy. In the previous paragraphs we indicated the importance of energy feedback to inform the users on their behaviour, leading to a reduction of this energy wasting behaviour. We also noticed that this feedback is most effective when it is provided close to the actual behaviour [10],[11].

Key in this context could be the so-called smart appliances. These appliances are designed to work within smart energy grids. A necessity for the implementation of these applications is the availability of a smart meter in the house. Refrigerators, freezers, washing machines, clothes dryers and dishwashers are amongst the most energy consuming appliances used in households. Smart technology can help reducing their energy use. An example of the application of smart technology is the possibility to partly or completely switch off an appliance during its runtime without any noticeable consequences for the consumer. Block et al. [12] state that $50 \%$ of the energy use in homes is generated by these kinds of appliances, such as refrigerators and washing machines. More generally, in all appliances that need energy, but are flexible in terms of the moment at which this energy is delivered, this kind of technology can be integrated [13].

Another possibility is more active feedback from the appliance itself (for example a washing machine) to the user on energy costs at the moment of use, suggestions to postpone a task and schedule it at a moment on which energy costs are lower (e.g. at night) or when renewable energy is available.

However, the question here arises to what extent the consumer will allow interference of these machines into their life. While these applications of smart technology might be important to reduce household energy consumption in a substantial way, it is important to keep the consumer's attitudes and opinions in mind, especially in terms of their control over these, in a certain way, self regulating devices.

An important study that tries to discover the consumers' attititude towards these smart appliances is Smart-A (http://www.smart-a.org), supported by the European Commission under the 'Intelligent Energy-Europe' Programme. It addresses in particular the issue of smart energy loads, determining the degree of possibility for smart appliances to adapt or alter their operation to variations in the regional and local energy supply, complemented with user acceptance research and economic modeling. 
This study identifies some clear drivers and barriers when it comes to the use of smart appliances by customers and their willingness or flexibility to accept these kind of appliances [14] In general, by means of quantitative (survey) and qualitative (expert interviews, focus group interviews) user research in several European countries, the study reveals a high acceptance degree when it comes to the use of smart appliances, but the economic advantages are far more imperative than the ecological ones, and price-related issues such as ROI and purchase price are of major importance. Furthermore, the study also demonstrates that end-users are not always willing to change their daily pattern or habits. As to mention one simple and clear example: the respondents stress the need of short interruption cycles when it comes to washing machines, because the respondents do not wish to leave their wet laundry in the washing machine for hours. In addition, the respondents stress the need of self-control when it comes to the operation of these domestic smart appliances.

In light of the future developments when it comes to smart grids and smart appliances, the Smart-A project offers some interesting findings. However, after scrutinizing the methodology of the user acceptance/adoption research, some major shortcomings must be mentioned: the bad representativeness of the survey research sample with an overrepresentation of people working in the academic sector, the high acceptance percentage of smart appliances because of the use of one-intention-based questions that result in bias, and in general the skewness concerning socio-demographic variables and parameters, such as the overrepresentation of middle-aged men who did not have any children living at home. In short, taking these comments into consideration, other methodological approaches for assessing user acceptation are desirable.

\section{GETTING TO KNOW THE USER: AN INNOVATIVE METHODOLOGICAL SET-UP}

\section{A. Many studies, fragmented answers}

The former paragraphs already demonstrated that users are an important target group when studying concepts such as smart metering or smart appliances. As literature shows, several studies try to grasp the customers' opinion and attitude about energy efficiency and/or the function of smart metering in this process, or they map out the energy behaviour. These studies are of course quite diverse in nature and focus on both organisational and residential contexts[15],[16],[17],[18],[19]. In Flanders, institutions such as VEA (Vlaams Energie Agentschap) and VREG (Vlaamse Reguleringsinstantie voor de Electriciteits- en Gas markt) frequently monitor the energy market by means of customer surveys.

Most of the aforementioned studies make use of the survey methodology. Nevertheless, the way in which these surveys are being conducted differs greatly. Most of them are limited to a study of mere descriptive items, including variables such as household details, possession of different domestic appliances, building types, electricity consumption, and so on. The surveys are often conducted online or by phone, classified as CATI (computer assisted telephone interview) and indeed the question arises whether variables about energy consumption levels or financing can be reliably questioned and answered this way. After all, asking people by phone questions concerning their meter reading must certainly lead to a lot of guesswork. VEA for example uses the CAPI method (computer assisted personal interview) for their monitoring studies, which is a more reliable method to obtain as much correct information as possible.

Another problem with most of these studies is the fact that they are not based on theoretical assumptions or valid measurement batteries. The questions are institution-specific and pragmatic. And here again the use of one-intention based questions for assessing user adoption or user acceptance (e.g. to what extent would you make use of this or that technology?) inevitably leads to false realities[20].

As a consequence, in order to assess the user acceptance of smart metering and smart appliances and at the same time trying to collect as much information as possible for defining the right communication platform and content to increase user awareness, more variables must be measured and combined. The following paragraphs describe the methodological set-up that will be used in Flanders to fill this gap, combining the results of energy monitoring and user interrogation.

\section{B. Methodology}

In order to provide users with communication campaigns about smart grids, energy efficiency and smart appliances, our study aims to profile different types of households and assesses their attitude towards smart appliances. For this purpose, two types of data will be correlated: data coming from synthetic load profile meters in different households and data originating from a user survey in households that possess these synthetic load profile meters. This way, questions about the correct level of energy consumption can be avoided in the survey, as the database with the synthetic load profile metering contains this information in a very detailed and absolutely correct way.

The user survey will be conducted from March 2010 until May 2010, spread over Flanders. The target sample size is 500 households, taking into account different types of households such as young singles, families with young children, families with grown-up children and retired people. As already mentioned, all these households will possess synthetic load profile meters, provided by Eandis or Infrax, so as to make the combination and correlation of the user survey data with the synthetic load profile meters database. Furthermore, the survey aims at a 50/50 division when it comes to gender, given that women and men might have other opinions when it comes to energy efficiency measures and/or the use of smart appliances. In general, the questionnaire contains information about building types, mobility, insulation measures, heating, lightning, energy patterns, domestic appliances, ICT and multimedia, ecological behavior, ecological attitude, smart appliances and several socio-demographic parameters like gender, age, profession or income, allowing this way a 
professional and detailed correlation of different variables.

\section{Research goals}

The following paragraphs elaborate more on the specific goals of this ongoing research, which are the profiling of households and an impression measurement of smart appliances.

\section{1) Profiling the households}

The basic aim of our research is to get a profound profiling of Flemish households with regard to their ecological attitudes and behaviour. We will be able to connect these profiles with their actual energy use, ownership of electronic appliances, current measures of energy consumption reduction and so on. Environmental Behaviour $(E B)$ will be measured using the General Ecological Behaviour scale as developed by Kaiser and Wilson [21]. We adapted this scale to some extent, to make it more adjusted to the goals of our research. This implies that we reformulated the items to make them measure the $E B$ of the household instead of that of one person in the household. Furthermore, some of the items were left out and replaced by others to insure the topicality of the scale.

\section{2) Impression of smart appliances}

We are also interested in the impression Flemish households have of smart appliances. We will study this by using the Technology Acceptance Model (TAM) [22],[23]. This model was specifically designed to measure the acceptance of information systems and ICT. It has been used in a wide variety of studies (a.o. [24],[25],[26],[27],[28],[29]). The key constructs of this model are Perceived Ease of Use (PEoU), Perceived Usefulness (PU) and Behavioural intention (BI). $P E O U$ refers to the degree in which a potential user expects that a new technology will be easy and not too complex to use. $P U$ refers to the degree in which the potential user expects that the new technology will be useful and will deliver advantages compared to the present way of working. The baseline behind this model is that the intention to use $(B I)$ can be predicted by $P E O U$ and $P U$. This behavioural intention will influence the actual use of the new technology. Figure 1 shows the Technology Acceptance Model as we intend to use it.

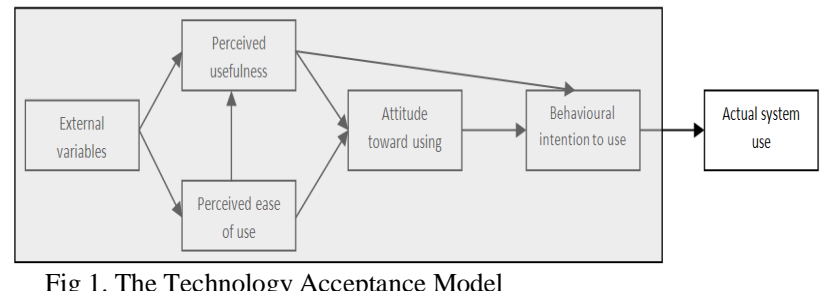

In our research we will not be able to measure the actual system use, since smart appliances do not yet exist in the households. Therefore, we will use a reduced TAM-model, with an exclusion of the actual behaviour. Certainly, this is not a problem for our research since the basic aim is to get an impression of what the respondent's attitude and intention towards smart appliances is. Key in this context is that we provide them with a clear description of what smart appliances are, what they can do and what the implications of using them will be.

In the final model we will try to examine what the influence is of a consumers Environmental Attitude (EA), Innovativeness $(I)$ and their - what we call - Perceived Personal Control (PPC) over smart appliances, on their overall perception of these smart appliances. We will measure $E A$ using the revised New Ecological Paradigm (NEP) [30],[31]. The idea behind this scale is rooted in the beliefs about "humanity's ability to upset the balance of nature, the existence of limits to growth for human societies, and humanity's right to rule over the rest of nature" [30]. The scale has proven to be successful in discriminating true environmentalists from the general public.

A person's general Innovativeness with regard to new technology will be measured by using the Technology Readiness Scale, which provides us with an overall index related to one's attitude towards new technology. The potential user's Perceived Personal Control over a smart appliance will be measured by using 4 items related to control. The items we included were: I think these smart appliances leave not much control to the user, I have doubts about the safety of these smart appliances (e.g. fire), I think using these smart appliances will disrupt my rhythm of life, I believe these smart appliances will cause a violation of my privacy.

To conclude, the combination of these different methodological techniques will allow us to gain a clear insight in the willingness of consumers to accept different kinds of measures when it comes to smart metering and smart appliances in their daily life, as to have an efficient user adoption in the future. 
REFERENCES

"Commission Recommendation of 9.10.2009 on mobilising Information and Communications Technologies to facilitate the transition to an energyefficient, low-carbon economy," European Commission, 2009.

[2] I. Mansouri-Azar, M. Newborough, and D. Probert, "Energy-consumption in UK domestic households: impact of domestic electrical appliances," Applied Energy, vol. 54, pp. 211-285, 1996.

[3] J. K. Dobson and J. D. Griffin, "Conservation effect of immediate electricity cost feedback on residential consumption in behaviour," in 7th ACEEE Summer Study on Energy efficiency in Buildings, Washington DC, 1992.

[4] T. Ueno, F. Sano, O. Saeki, and K. Tsuji, "Effectiveness of an energy-consumption information system on energy savings in residential houses based on monitored data," Applied Energy, vol. 83, pp. 166183, 2006.

[5] C. Fischer, "Feedback on household electricity consumption: a tool for saving energy?," Energy Efficiency, vol. 1, pp. 79-104, 2008.

[6] J. Froehlich, "Promoting Energy Efficient Behaviors in the Home through Feedback: The Role of HumanComputer Interaction," in International Conference on Human-Computer Interaction San Diego, 2009.

[7] G. Wood and M. Newborough, "Dynamic energyconsumption indicators for domestic appliances: environment, behaviour and design," Energy and Buildings, vol. 35, pp. 821-841, 2003.

[8] W. F. Van Raaij and T. M. M. Verhallen, "A behavioral model of residential energy use," Journal of Economic Psychology, vol. 3, pp. 39-63, 1983.

[9] G. Brandon and A. Lewis, "Reducing Household Energy Consumption: A Qualitative and Quantitative Field Study," Journal of Environmental Psychology, vol. 19, pp. 75-85, 1999.

[10] D. Parker, D. Hoak, A. Meier, and R. Brown, "How much energy are we using? Potential of residential energy demand feedback services," in Summer Study on Energy Efficiency in Builiding, Pacific Grove, 2006.

[11] P. C. Stern, "New Environmental Theories: Toward a Coherent Theory of Environmentally Significant Behavior," Journal of Social Issues, vol. 56, pp. 407424, 2000.

[12] C. Block, D. Neumann, and C. Weinhardt, "A Market Mechanism for Energy Allocation in Micro-CHP Grids," in 41st Annual Hawaii International Conference on System Sciences (HICSS), Hawaii, 2008.

[13] J. Short and S. Leach, "Using smart appliances to provide peak-load management and increase the efficiency of the electricity network," in EEDAL '06 London, 2006.

[14] W. Mert, "Consumer acceptance of smart applicances," in WP5 report from Smart-A project, 2008.
C. E. Association, " Homeowners turn to technology to help cut energy costs," in EC\&M. vol. 108, 2009. S. Erkki, "Demand Response activities in Finland," Oslo, 2005.

E. Bonneville and A. Rialhe, "Demand side management for residential and commercial endusers," in Efficiency \& Eco-design, May 2006.

E. De Groot, M. Spiekman, and I. Opstelten, "Dutch research into user behavior in relation to energy user of residences," in PLEA 25th Conference on Passive and Low Energy Architecture Dublin, 2008.

F. Bartiaux, G. Vekemans, K. Gram-Hanssen, D. Maes, M. Cantaert, B. Spies, and J. R. Desmedt, january 2006, " Socio-technical factors influencing residential energy consumption," 2006.

R. Bennett and R. Kottasz, "The shape of things to come: how marketing service

organisations anticipate the future," Journal of Targeting, Measurement and Analysis for Marketing, vol. 9, pp. 309-325, 2001.

F. Kaiser and M. Wilson, "Assessing People's General Ecological Behavior: A Cross-Cultural Measure," Journal of Applied Social Psychology, vol. 30, pp. 952-978, 2000.

F. D. Davis, "A technology acceptance model for empirically testing new end-user information systems : theory and results," Cambrigde, MA: Massachussets Institute of Technology, 1986.

F. D. Davis, R. P. Bagozzi, and P. R. Warshaw, "User Acceptance of Computer Technology: A Comparison of Two Theoretical Models," Management Science, vol. 35, pp. 982-1003, 1989.

V. Venkatesh, L. M. Maruping, and S. A. Brown, "Role of time in self-prediction of behavior," Organizational Behavior and Human Decision Processes, vol. 100, pp. 160-176, 2006.

V. Venkatesh, S. A. Brown, L. M. Maruping, and H. Bala, "Predicting Different Conceptualizations of System Use: The Competing Roles of Behavioral Intention, Facilitating Conditions, and Behavioral Expectation," in MIS Quarterly. vol. 32: MIS Quarterly \& The Society for Information Management, 2008, pp. 483-502.

D. Gefen and D. W. Straub, "Gender Differences in the Perception and Use of E-Mail: An Extension to the Technology Acceptance Model," MIS Quarterly, vol. 21, pp. 389-400, 1997.

P. J. Hu, P. Y. K. Chau, O. R. L. Sheng, and K. Y. Tam, "Examining the technology acceptance model using physician acceptance of telemedicine technology," J. Manage. Inf. Syst., vol. 16, pp. 91$112,1999$.

M. Koufaris, "Applying the Technology Acceptance Model and Flow Theory to Online Consumer Behavior," Info. Sys. Research, vol. 13, pp. 205-223, 2002.

A. L. Lederer, D. J. Maupin, M. P. Sena, and Y. Zhuang, "The technology acceptance model and the World Wide Web," Decision Support Systems, vol. 29, pp. 269-282, 2000. 
[30] R. E. Dunlap, K. D. Van Liere, A. G. Mertig, and R. Emmet Jones, "Measuring Endorsement of the New Ecological Paradigm," Journa of Social Issues, vol. 56, pp. 425-442, 2000.

[31] K. D. Van liere, "The New Environmental Paradigm: A Proposed Measuring Instrument and Preliminary Results," The Journal of Environmental Education, vol. 9, p. 10, 1978. 